\title{
Ariel en la Gran Guerra: notas sobre las crónicas europeas de José Enrique Rodó
}

\author{
Cristina Beatriz Fernández \\ Universidad Nacional de Mar del Plata (UNMDP) \\ Consejo Nacional de Investigaciones Científicas y Técnicas (CONICET)
}

Título: Ariel en la Gran Guerra: notas sobre las crónicas europeas de José Enrique Rodó.

Resumen: El objetivo de este trabajo es analizar, a partir de las crónicas de viaje que José Enrique Rodó publicó en Caras y caretas durante los años 1916-1917, algunos aspectos derivados de su visión de Europa, en el contexto de la primera guerra mundial. Entre esos aspectos, destacamos: la función magisterial que adquiere la crónica de viaje, firmada por un mentor intelectual de la talla de Rodó, en un medio de difusión de alcance masivo como la revista Caras y caretas; la relación entre esas crónicas y otras noticias de actualidad insertas en la publicación; el desencanto respecto de la civilización europea que comporta, en parte, el estallido de la guerra y, como consecuencia de ello, la construcción de una utopía que vincula al continente americano con el futuro de la raza latina, sobre la base de procedimientos alegóricos.

Palabras clave: José Enrique Rodó, Crónicas, Europa, Primera Guerra Mundial, Caras y Caretas.

Fecha de recepción: 25/10/2015.

Fecha de aceptación: 8/11/2015.
Title: Ariel in the First World War: Notes about the European Chronicles of José Enrique Rodó.

Abstract: The aim of this paper is to analyse the travel chronicles written by José Enrique Rodó and published in the magazine Caras y caretas in 1916 and 1917. Some features of these chronicles are derived from Rodó's vision of Europe in the years of the First World War. Our analysis focuses on these questions: the magisterial function of the chronicles published in the magazine Caras y caretas, devoted to a massive public, specially when signed by a prestigious intellectual such as Rodó; the relationship between the literary chronicles and the news included in the magazine; the European civilization disenchantment caused by the War and, as a result of this, the construction of an utopian future for the latin race in Hispanic America, construction based on allegorical procedures.

Key words: José Enrique Rodó, Chronicles, Europe, First World War, Caras y Caretas.

Date of Receipt: 25/10/2015.

Date of Approval: 8/11/2015. 
El 23 de septiembre de 1916 apareció, en la revista Caras y caretas de Buenos Aires, la primera de una serie de crónicas que enviaba desde Europa José Enrique Rodó. Esa serie consistió, finalmente, en veintidós notas de viaje, impresas en la mencionada revista o en su suplemento ilustrado, Plus Ultra. Póstumamente, esos escritos fueron compilados por Vicente Clavel, el editor español de Rodó, en el libro El camino de Paros. Una última crónica sobre Palermo, que el autor dejó inconclusa, se dio a conocer recién en 1922, en el diario La Nación de Buenos Aires ${ }^{1}$.

Muchos son los aspectos que merecen ser considerados en este corpus de crónicas rodonianas, pero tomaremos como eje para este trabajo el impacto de la primera guerra mundial en sus reflexiones sobre la cultura hispanoamericana, siempre en el marco de su concepción de la civilización latina.

1 Según Emir Rodríguez Monegal, la edición española de El camino de Paros mezcla las crónicas publicadas en Caras y Caretas con otros artículos misceláneos, además de que no incluye tres de las crónicas aparecidas en el semanario porteño. La edición valenciana de El camino de Paros se divide, en efecto, en dos secciones: "Meditaciones" y "Andanzas", aunque sólo corresponden a las crónicas de viaje publicadas en Caras y caretas y en Plus Ultra los textos agrupados bajo el segundo título. La edición de las obras completas de Rodó preparada por Alberto José Vaccaro (Buenos Aires, 1948), rescataba dos crónicas más, olvidadas en las páginas de la revista, pero es recién con la edición preparada por Rodríguez Monegal para la editorial Aguilar que aparecen todos los textos de Caras y caretas y que se deslindan los artículos circunstanciales que no correspondían al corpus cronístico. Una última crónica, sobre Palermo, no fue publicada tampoco en Caras y caretas: quedó inconclusa y fue transcrita del borrador para darse a conocer en el periódico La Nación, de Buenos Aires, el 24.XII.1922, de donde la recogió Rodríguez Monegal. Véanse Emir Rodríguez Monegal, "Prólogo" a José Enrique Rodó, El camino de Paros, en Obras completas, Madrid, Aguilar, 1957, pp. 1183-1184; José Enrique Rodó, El camino de Paros, Valencia, Cervantes, 1919 [disponible en línea], Biblioteca Virtual Miguel de Cervantes, http://www.cervantesvirtual.com/obra/el-camino-de-paros-meditaciones-y-andanzas--0/ (consulta efectuada el 20-10-2015). Para nuestro trabajo, seguimos la edición de Rodríguez Monegal, que iremos confrontando con la versión original de las crónicas en Caras y Caretas, Buenos Aires, 1916-1917 (disponible en línea): Biblioteca Digital Hispánica, http://www.bne.es/es/Catalogos/BibliotecaDigitalHispanica/Inicio/index.html (consulta efectuada el 20-10-2015). 


\section{Noticias de actualidad en CARAS Y CARETAS: Europa EN GUerra}

Como ocurre con tantos autores del período modernista hispanoamericano, Rodó se relacionó tempranamente con las revistas culturales: ya en 1895 su nombre consta como uno de los fundadores de la Revista nacional de literatura y ciencias sociales, en Montevideo. Si expandimos la mirada hacia otras formas de las publicaciones periódicas, como los diarios, encontraremos su firma en empresas periodísticas como El Orden, La Razón, El País, El Plata y El telégrafo, todos periódicos uruguayos. Sin embargo, es en El Día, el órgano político de José Batlle y Ordóñez, donde colaboró asiduamente entre 1901 y 1906, hasta distanciarse políticamente del fundador del batllismo. A partir del año siguiente, 1907, actuó como corresponsal de La Nación de Buenos Aires, cuyas columnas compartía con Rubén Darío. De hecho, Rodó no abandonaría hasta su muerte su tarea de colaborador en revistas y periódicos ${ }^{2}$.

Fue precisamente su vinculación con estos emprendimientos editoriales propios de la modernización cultural lo que le brindó la oportunidad de concretar el tan ansiado viaje a Europa, adonde llegó como corresponsal de la revista argentina Caras y caretas $^{3}$ en 1916. Para entonces, $C y C$ era una de las publicaciones periódicas más importantes, de las que estaban dirigidas a un público amplio. Fundada en 1898 por el escritor de cuentos populares José S. Álvarez (Fray Mocho), el dibujante Manuel Mayol y el periodista español Eustaquio Pellicer, el semanario se publicó hasta 1939, con sostenido éxito comercial ${ }^{4}$.

2 Véase Fernando Aínsa, "La perspectiva americana de José Enrique Rodó desde el Capitolio de Roma”, CUYO. Anuario de Filosofía Argentina y Americana, 17 (2000), p. 81.

3 En adelante, $C y C$.

4 Eustaquio Pellicer había fundado una primera Caras y caretas en Uruguay, en 1890, que salió hasta 1897, bajo la dirección sucesiva de Charles Schültz y Arturo Giménez Pastor. Luego, Pellicer emigró a Buenos Aires, ingresó como periodista en La Nación e instaló la primera sala de cine porteña. En 1898 convocó a Bartolomé Mitre y Vedia, exdirector de La Nación e hijo de su fundador, para el nuevo emprendimiento de Caras y Caretas. Pero Mitre y Vedia excusó su participación cuando el primer número estaba ya en prensa y entonces Pellicer se asoció a otro periodista de $L a$ Nación, José S. Álvarez. En 1904, Pellicer se retiró de la revista y pasó a dirigir PBT. 
Fue en el año 1898 cuando una circular de cuatro páginas anunciaba la inminente aparición del semanario, que ya desde el inicio se presentaba como una publicación carente de espíritu doctrinario:

¿Que cuál es nuestro programa? Si le tuviéramos, te lo daríamos hasta con incisos; pero es el caso que lo único que se nos ha ocurrido hacer por el momento, es una gran provisión de coraje para dar este primer paso

\section{En la escabrosa senda por donde han ido \\ todos los editores \\ que se han "fundido».}

No es, por otra parte, necesario el programa a una publicación que se presenta con los apelativos de festiva, literaria, artística y de actualidades, pues en ellos se condensa cuanto pudiera decirse acerca de su índole, tendencias y plan de labor ${ }^{5}$.

Es así que $C y C$ tomó como modelo los magazines que se publicaban en Inglaterra y en Estados Unidos, base sobre la cual la dirección llevó a cabo un proyecto criollo de semanario popular que, haciendo coincidir en sus páginas materiales y formas tan diversas como la noticia, la crónica, la página de entretenimientos, el relato costumbrista, el cuento o la poesía, desempeñaría un papel mediador entre los niveles cultos y populares y avanzaría con firmeza frente a las propuestas culturales hegemónicas de sesgo más tradicional. El sistema misceláneo del magazine propició el consumo de un público recientemente incorporado a la lectura, pero también funcionó como un ámbito de promoción de firmas literarias como las de Leopoldo Lugones, Roberto Payró, Martiniano Leguizamón, Enrique García Velloso, Arturo Costa Álvarez, Rubén Darío, Ricardo Palma, Juan Pablo Echagüe u Horacio Quiroga. De este modo, la revista ofrecía a grupos sociales en ascenso, cuyo status requería una legitimación

Para esta información, remitimos a Geraldine Rogers, Caras y caretas. Cultura, política y espectáculo en los inicios del siglo XX argentino, La Plata, Edulp, 2008, especialmente al capítulo "El proyecto y su forma", pp. 27 y ss.

5 Apud Geraldine Rogers, op. cit., p. 31. 
cultural, una cuota de capital simbólico, implicado en las firmas de autores literarios prestigiosos o en las manifestaciones artísticas. Ese capital simbólico se transfería a un público que, sin necesidad de contar con una formación intelectual previa de gran exigencia, podía tomar contacto con fragmentos de cultura estética y literaria sagazmente dosificados por la revista: recordemos, por ejemplo, que varios números de esta publicación ofrecían réplicas en color de obras pictóricas que se podían recortar para encuadrar y decorar las viviendas de sus lectores ${ }^{6}$.

La vinculación del escritor con las publicaciones periódicas y la tarea periodística, que a esta altura, sabemos que fue sustancial para el desarrollo de la prosa modernista -como lo han demostrado Susana Rotker y Julio Ramos ${ }^{7}$, entre otros- es puesta en primer plano por el mismo Rodó cuando, desde la ciudad italiana de Pisa, se incluye en una genealogía de periodistas que cuenta con nombres ilustres, como el de Byron:

... Y fue asimismo aquí [en Pisa] donde [Byron] concertó con Shelley, que viajaba como él por Italia, y con otro escritor amigo, Leigh Hunt, la publicación de un periódico en Londres. -Sabedlo, compañeros de profesión, los que no lo sabíais. El espíritu más rematadamente aristocrático de la literatura del siglo XIX militó también en nuestro gremio. ¡Lord Byron redactor de periódicos! [... $]^{8}$.

Volviendo a la revista, un rasgo no menor que caracterizó a $C y C$ fue su condición expresa de insertarse, como producto cultural, en el mercado

6 Seguimos para esta síntesis a Geraldine Rogers, "Caras y caretas: la lógica de la integración”, Orbis tertius, III, 6 (1998) [disponible en línea] http://www.orbistertius.unlp. edu.ar [consulta efectuada el 13-7-2015]. Esta crítica considera que "Caras y Caretas contribuyó a la creciente vulgarización de la cultura literaria en un momento en que acercar espacial y humanamente las cosas, adueñarse de los objetos culturales en la más próxima de las cercanías, empezaba a ser una de las principales aspiraciones sociales de carácter masivo" (Geraldine Rogers, Caras y caretas. Cultura, política y espectáculo en los inicios del siglo XX argentino, p. 273).

7 Susana Rotker, "La crónica modernista y la crítica literaria” y "El lugar de la crónica", en La invención de la crónica, México, FCE, 2005, pp. 13-27 y 89-135; Julio Ramos, Desencuentros de la modernidad en América Latina. Literatura y política en el siglo XIX, México, FCE, 1989.

8 José Enrique Rodó, “Recuerdos de Pisa”, en Obras completas, p. 1206. Recordemos que, desde 1908, Rodó presidía el Círculo de la Prensa en Uruguay. 
de los bienes simbólicos, y ello hace que sea explícita en sus páginas la exhibición de las condiciones y problemas concernientes a su sustentabilidad económica. Un pasaje ilustrativo al respecto lo encontramos en el número almanaque de 1898, donde se informa de que

... el buen resultado económico de la revista (derivado de su copiosa venta y de la considerable cantidad de avisos que el comercio trae a sus páginas, atraída por el aliciente de su notoria circulación) nos permite solicitar y retribuir discretamente el trabajo literario y artístico más selecto, buscándolo donde se halla, con lo cual se estimula y ennoblece la producción intelectual del país, que es todavía la que menos mercado y alicientes materiales tiene entre nosotros, constreńida por lo general a malbaratarse deplorablemente, cuando no a darse gratis para lograr publicidad?.

Así, $C y C$, pionera en la prensa de precio económico y accesible a una amplia audiencia, fue uno de los primeros medios que pagó en forma regular las colaboraciones literarias, a la vez que las leyes del mercado pasaron a regir la configuración de las obras, en una constante negociación entre el poder simbólico y el mercantil ${ }^{10}$. Un ejemplo de esta capacidad de mecenazgo en el seno de una economía de mercado, es precisamente el contrato de Rodó como corresponsal de la revista en Europa, una condición de producción que nuestro autor exhibe en la prosa de sus crónicas, en pasajes como aquel que dice: "antes de enviar a Caras y caretas mis impresiones de esta conversación" ${ }^{11}$. Téngase en cuenta, además, que la industria de la prensa y el incremento de los viajes se desarrollaron paralelamente, y que eso colaboró en la consolidación del género periodístico de las crónicas

9 Caras y caretas, Buenos Aires, número almanaque, 1-12-1898, citado en Geraldine Rogers, Caras y caretas, p. 63.

10 Es ilustrativa, al respecto, la anécdota según la cual la brevedad y concisión del cuento, rasgo del género que Horacio Quiroga incluyó en su famoso "decálogo", respondía a una exigencia de Luis Pardo, el Jefe de Redacción de $C y C$, motivada por las limitaciones de espacio en las páginas que la publicación dedicaba a la ficción, un espacio que generalmente era compartido por alguna ilustración. Cabe aclarar que todas las crónicas de Rodó publicadas en $C y C$ están acompañadas por fotografías y/o ilustraciones.

11 José Enrique Rodó, “[Portugal] Una entrevista con el presidente”, en Obras completas, p. 1189. 
o notas de viaje, que desde fines del siglo XIX merecían una columna estable en gran parte de los periódicos y revistas latinoamericanos. Como ilustra el caso de Rodó, muchas de esas crónicas de viaje fueron publicadas más tarde en libros, ya que su condición efímera de género periodístico se balanceaba con la firma prestigiosa que la suscribía, lo cual le garantizó una relativa supervivencia ${ }^{12}$. De este modo, publicaciones como $C y C$ eran emblemáticas de un proceso de modernización cultural que fue coetáneo -e incluso, precedió en unos años- a los procesos de democratización política en Argentina, colaborando en la ampliación de del espectro de lectores y dirigiéndose a un público que era entendido, primariamente, como un consumidor.

Sabemos que el modernismo estuvo vinculado, desde su génesis, con la prosa periodística, muy a pesar del tópico de la confrontación entre la alta cultura espiritualista y el circuito popular o comercial, actitud que no fue compartida por $C y C$, como lo evidencia el fragmento de su programa editorial citado líneas arriba, y que la diferencia claramente del afán de mantenerse "lejos de todo propósito utilitarista", como predicaba el Mercurio de América, o del intento de defender "la divina Belleza" del avance de las "tendencias utilitarias", como se proponía la Revista de América". En este sentido, conviene relativizar la distinción entre una zona de discursos producidos por la alta o la baja cultura, en un intento de esquematizar modos de producción cultural tributarios de distintos estratos sociales. Las revistas fueron, en efecto, zonas de intersección y permeabilidad que coadyuvaron a la profesionalización literaria y al desarrollo de un público de clase media urbana ${ }^{14}$. Es en esta zona de producción discursiva tributa-

12 Sobre el tema de la firma, es interesante notar que en las crónicas que nos ocupan, se reproduce la firma original de Rodó. Para Geraldine Rogers, la reproducción facsimilar de la letra manuscrita era una forma de preservar el aura de los literatos destacados en un contexto donde era cada vez más fácil que cualquier escritura alcanzara a verse impresa, incluidos los textos de los lectores que participaban en diversos concursos organizados por la misma revista (Geraldine Rogers, Caras y caretas, p. 300). Sobre la crónica y la relación prensa / libros, Beatriz Colombi, "Prólogo" a Cosmópolis. Del flâneur al globe-trotter, Buenos Aires, Eterna Cadencia, 2010, pp. 11-34.

13 Citados en Geraldine Rogers, Caras y caretas, p. 289.

14 En palabras de Geraldine Rogers, Caras y caretas, p. 104, "Caras y Caretas, destinada a un público heterogéneo de todas las clases sociales, formó parte de esa zona de cruces en la industria cultural emergente. Era leída por señoras y mucamas, propieta- 
ria de la tecnologización y de los procesos de masificación, donde tiene su emergencia la crónica modernista, que en su heterogeneidad representa las contradicciones y tensiones entre el discurso literario y otros discursos sociales que interpelaban y limitaban su virtual autonomía ${ }^{15}$.

Parte central del proyecto editorial de $C y C$ era su interés por las noticias de actualidad, y de allí el afán por ofrecer al lector información sobre los eventos nacionales e internacionales que se estaban produciendo. Es interesante, en consecuencia, observar el modo en que algunos temas abordados por los cronistas literarios, como ocurre en el caso emblemático de Rodó, forman sistema con noticias que aparecen en otras páginas de la revista, como los eventos concernientes a la primera guerra mundial y sus derivaciones ${ }^{16}$. Por ejemplo, en diciembre de 1916, la revista incluye

rios y jornaleros, empleados y comerciantes, y por los hijos de todos ellos. Hasta los miembros encumbrados del circuito letrado la frecuentaban como lectores: Joaquín V. González declaró gozar en sus páginas del género festivo y la caricatura, a su juicio la más deliciosa de las artes".

15 Julio Ramos, op. cit., p. 12.

16 Limitándonos solamente a los números donde salieron publicadas las crónicas rodonianas, encontramos las siguientes notas periodísticas y cuentos, todos relacionados con la Primera Guerra Mundial, su desarrollo en el frente o sus consecuencias en la vida cotidiana y en el desarrollo científico y tecnológico: "El general Sir Douglas Haig", "Cómo emplea su día Benedicto XV", "La hora trágica de Bulgaria", "Los ciegos de la guerra" (CyC, XIX, 938, 23-9-1916), "Caras y caretas en Rusia", "Los héroes modestos de Francia", "Desde la Gran Bretaña", "Desde Corfú. Los serbios a la lucha" (CyC, XIX, 941, 14-10-1916), "Las ciudades, las aldeas y los campos de Bélgica", "La ofensiva italiana en el Isonzo", "Los oídos del submarino" $(C y C$, XIX, 943, 28-10-1916), "Argentinos en la guerra", "Los héroes del patriotismo húngaro", "Caras y caretas en Italia. Los médicos en el frente" (CyC, XIX, 944, 4-11-1916), "Las ciudades, las aldeas y los campos de Bélgica", "Caras y Caretas en los Balcanes. Salónica", "Los efectos de los gases asfixiantes", "Episodios de la guerra europea" (CyC, XIX, 945, 11-11-1916), "Episodios interesantes", "Un útil invento italiano. La rápida integración de cuerpos extraños en las heridas", "Cuentos de la guerra" (CyC, XIX, 946, 18-11-1916), "Argentinos en la guerra", "El emperador de Austria - Hungría Francisco José”, "Desde Bélgica invadida. El rey heroico”, "Caras y Caretas en Italia. El fin de un héroe sin pierna. Conversando con sus padres", "Episodios interesantes" (CyC, XIX, 948, 2-12-1916), "Desde Italia. Visiones de guerra", "Las ciudades, los pueblos y los campos de Bélgica invadida", "Episodios interesantes", "Cuentos de la guerra. La 'madrina", "El rey Constantino y Venizelos. Frente a frente" (CyC, XIX, 949, 9-12-1916), "El escultor Leonardo Bistolfi, en Gorizia”, 
una nota donde consta la visita del escultor italiano Leonardo Bistolfi a Gorizia, una zona que estuvo en el frente de combate en la primera guerra. Poco después, en enero de 1917, se publica la crónica de Rodó "Un documento humano", que glosa, para el lector de $C y C$, el diario de un oficial austríaco que había caído prisionero en Gorizia, diario que fue leído en una reunión intelectual que tuvo lugar, precisamente, en el taller de Bistolfi ${ }^{17}$.

Desde su lugar de intelectual ya consagrado y que escribe para un incipiente público de masas, Rodó comparte con los lectores de $C y C$ su visión de Europa y, particularmente, de la guerra que estaba expandiéndose por ese continente ${ }^{18}$. Ya desde 1914, el escritor uruguayo había quedado a cargo, en el periódico El Telégrafo, de una sección titulada "La guerra a la ligera” y que firmaba con el seudónimo de Ariel. Pero ahora, la visión de la guerra tendrá lugar desde un ángulo más cercano, puesto que el autor se encuentra en la misma Europa, aunque su mirada nunca pierde de vista la perspectiva americana. Así, cuando a su paso por Barcelona se encuentra

"Episodios de la gran guerra", "Desde Rumania. Con el ejército de von Falkenhayn", "Mr. Lloyd George, en el frente inglés, en Francia", "El derecho de las madres" $(C y C$, XIX, 952, 30-12-1916), "Los rayos Roentgen y las balas", "Desde Roma. Escolares modelos", "Sévres y la guerra. En vez de arte, industria. Jarrones para ácidos", "Episodios interesantes" (CyC, XX, 954, 13-1-1917), "El humor de los combatientes", "Caras y caretas en Italia. La dura lucha en el Carso", "De todo un poco" ( $C y C, \mathrm{XX}$, 955, 20-1-1917), "Los efectos de la guerra en la mujer" (CyC, XX, 956, 27-1-1917), "Notas curiosas", "América en la guerra" (CyC, XX, 958, 10-2-1917), "Curiosidades y anécdotas" (CyC, XX, 964, 24-3-1917), "La guerra vista desde Londres", "Caras y caretas en Italia. La Sicilia durante la guerra", "Los repatriados" $(C y C, \mathrm{XX}, 966$, 7-4-1917), "América en la guerra", "Caras y caretas en Italia. Desde las trincheras a las casas lejanas" (CyC, XX, 967, 14-4-1917), "Caras y Caretas en Italia. Con los hermanos Raicevich", "Cuentos de la guerra. Los dos gemelos", "Los canadienses en la guerra", "Nuevo servicio sanitario en la armada yanqui" ( $C y C, \mathrm{XX}, 970,5-5-$ 1917), "Una historia increíble" (CyC, XX, 973, 26-5-1917), "La aviación después de la guerra", "La guerra desde Londres" (CyC, XX, 978, 30-6-1917).

$17 C y C$, XIX, 952, 30.XII.1916 y CyC, XX, 956, 27-1-1917.

18 Sobre este momento en la producción de Rodó, véanse Fernando Aínsa, op. cit., pp. 75-87; Giuseppe Bellini, "Rodó e il soggiorno italiano", en Storia delle relazioni letterarie tra l'Italia e l'America di lingua spagnola, Milano, Cisalpino-Goliardica, 1982, pp. 226233; y José Pablo Drews, "Estampas desde las trincheras: José Enrique Rodó y su lectura de la Gran Guerra”, Thémata. Revista de Filosofía, 48 (2013), pp. 135-142. 
con Rafael Vehils, destaca el emprendimiento que prepara este último,

... acompańado desde su cátedra de Oviedo por Rafael Altamira, una publicación de la mayor oportunidad e interés: una revista de estudios internacionales, donde, anticipándose a la solución del actual conflicto europeo, con las transformaciones que probablemente determinará y el nuevo orden que ha de resultar de él, se tenderá a señalar un ideal de política exterior para Espańa, una dirección consciente y sistemática de sus relaciones con el resto del mundo, incluyendo como parte preferente de ellas las que se refieren a los pueblos hispanoamericanos ${ }^{19}$.

Alternando con las crónicas de arte o la descripción de las bellezas naturales, el conflicto bélico se filtra en la prosa de Rodó quien, aunque no es un corresponsal de guerra, stricto sensu, trabaja como un cronista que observa y analiza la realidad europea para ofrecer una imagen vívida de la situación que se está produciendo allí. Por ejemplo, articula el elogio de las bellezas naturales de la isla de Capri con el impacto económico que la guerra ha causado en la región:

...Capri, como Sorrento, tenía, antes de la guerra, su más copiosa fuente de utilidad en su misma pintoresca belleza, que atraía anualmente a sus playas a muchos millares de viajeros, sin contar los potentados europeos y americanos que han levantado villas suntuosas en el filo de estas peñas y en la falda de estas colinas ${ }^{20}$.

Pero a la observación y el análisis de los sitios que visita, se suma la reelaboración de otras fuentes de información, como la misma prensa europea, de donde extrae anécdotas bélicas que reescribe, despojándolas de la crudeza que afectaría el buen gusto esperable en su prosa, para ofrecérselas al lector de $C y C$ :

El fondo heroico, que encubre esa sonriente máscara, da asidua razón de sí allá donde se lucha y se muere. Cien episodios lo manifiestan cada día. Contados en las reseńas de los periódicos o en las cartas

19 José Enrique Rodó, “En Barcelona”, Obras completas, p. 1190. La bastardilla es nuestra.

20 José Enrique Rodó, “Capri”, en Obras completas, p. 1246. 
de los soldados; dando motivo al comentario de los salones y de los corrillos populares, son la crónica donde rasgarán mañana su crisálida las leyendas de esta magna gesta patriótica. Un diligente periodista, el señor Giuseppe de Rossi, ha tenido el oportuno acuerdo de coleccionar los más interesantes y significativos de esos episodios, en un volumen que se lee con agrado y emoción ${ }^{21}$.

En consonancia con lo antedicho, la tragedia de la guerra es estetizada, y en una serie de microrrelatos compara sujetos y acciones con arquetipos literarios, como las picardías de algunos soldados que le recuerdan "la malicia" o "la travesura épica" de Ulises ${ }^{22}$, o convierte a un "niño sublime" que muere ayudando a los soldados de su país en una alegoría de la infancia patriótica y heroica: "No se sabe su nombre. No queda de él más que del pájaro abatido de la rama por el golpe del granizo. Glorifiquémosle dentro de la advocación simbólica del Gravoche de Víctor Hugo"23. Incluso los aspectos más crueles, morbosos o desagradables son mediatizados por la mirada estetizante del cronista, quien se pregunta "cuál sería el poeta capaz de poner en bellas rimas estos vientres destripados, estos pingajos de carne, estos torsos semideshechos, estos lodazales de sangre, estos sesos fuera de su cráneo" 24 .

Si la crónica de viaje ilustra un itinerario, también nos da a conocer las relaciones personales, políticas e intelectuales, del viajero, como lo muestra la crónica dedicada al diario del oficial austríaco apresado en Gorizia, ya mencionado arriba. Rodó obtiene el diario gracias a sus vinculaciones con los círculos literarios y artísticos de Turín, convirtiéndose en el mediador prestigioso entre esos cenáculos -que tienen puntos de encuentro, por ejemplo, en el taller del célebre escultor Bistolfi- y el lector de $C y C$, quien participa así, vicariamente, en los ámbitos de sociabilidad intelectual del mismo escritor-cronista:

... Este oficial llevaba en el bolsillo un cuaderno de memorias, un diario psicológico, donde había anotado sus impresiones de la vida de campamento y trincheras [...]

21 José Enrique Rodó, “Anécdotas de la guerra”, en Obras completas, p. 1220.

22 José Enrique Rodó, “Anécdotas de la guerra”, en Obras completas, p. 1220.

23 José Enrique Rodó, "Anécdotas de la guerra”, en Obras completas, p. 1221.

24 José Enrique Rodó, “Un documento humano”, en Obras completas, p. 1223. 
... Del teatro de la guerra pasó ese cuaderno - hasta hoy desconocido para el público- a ciertos círculos intelectuales de Turín.

Debo a la buena amistad del señor Camilo Ferrúa, el conocimiento de ese curioso manuscrito, que con su autorización ofrezco, brevemente comentado, a los lectores de Caras y caretas. Es, según se decía en tiempos del naturalismo, un admirable documento humano $[. . .]^{25}$.

No deja de ser un rasgo de distinción y sensibilidad estética que ese "documento humano" haya sido una lectura compartida "en el taller de Leopoldo [sic] Bistolf", donde se encuentra el cronista "rodeado de formas estatuarias que hablan del dolor y de la muerte". Asimismo, el rol mediador se exhibe en la adaptación del registro léxico de ese escrito, no nacido para la imprenta, para el gran público: "Explicables respetos me obligan, y es lástima, a suprimir o atenuar, en la traducción, palabras de brutal crudeza, toques de realismo feroz, que contribuyen a la cruel energía del original" 26.

\section{El DESENCANTO CIVILIZATORIO Y LA PROYECCIÓN ALEGÓRICA SOBRE LA REALIDAD AMERICANA}

Ya en la primera de las crónicas, "Cielo y agua”, Rodó introduce el tema americano al describir la exuberante bahía de Río de Janeiro calificándola como "el pórtico de América", cuyas formas

... sugieren la idea arquitectónica de un mundo que se abre, de un continente que compendia su infinitud y su carácter en un aspecto capaz de ser abarcado con los ojos. Por este arco triunfal debió de penetrar a la Atlántida soñada, para consagrarla en la historia, el genio latino $[\ldots]^{27}$.

La asociación de América con la herencia latina será una constante en las crónicas del viaje a Europa: aunque esté glosando las bellezas naturales o culturales, hablando de la guerra o la historia del viejo continente, Rodó

25 José Enrique Rodó, "Un documento humano”, en Obras completas, pp. 1221-1222. 26 José Enrique Rodó, "Un documento humano”, en Obras completas, p. 1222. 27 José Enrique Rodó, "Cielo y agua”, en Obras completas, p. 1185. 
no deja de poner en primer plano la filiación cultural de la América Hispánica con la lengua y la cultura latinas. La relación entre el tiempo pasado y la modernidad, por ejemplo, es una dicotomía que articula constantemente su visión de Europa, como queda en evidencia en el pasaje en que habla de la Barcelona moderna:

... Los barceloneses me hablan con orgullo del Ensanche, que es el barrio moderno; de sus majestuosas avenidas y sus frentes de mármol, y se afanan porque le conozca y admire. Nada más justificado que ese orgullo. Pero no sé si llego a hacerles comprender del todo que a un americano de la parte más nueva de América (y, añádase, por temperamento personal un poco nostálgico e idealizador de lo que queda atrás en el tiempo), debe interesarle, mucho más que todo aquel alarde de espléndida modernidad, la Barcelona que han dejado los siglos; la de las calles estrechas y tortuosas, por donde no pasan tranvías ni automóviles; la que evoca el recuerdo, ya del balcón del trovador, ya del sosiego del convento; la de la Casa Consistorial, y la Audiencia, y la Sala de Contrataciones de la Lonja; la de esa característica plazuela de la Catedral, que, con Rafael Vehils, recorrimos una tarde en que, a la verdad, me creí transportado por encanto a los días de Roger de la Flor y de los condes en guerra con turcos y con moros $[\ldots]^{28}$.

Una modernidad que ha llegado en forma conflictiva a la América Hispana y que Rodó no puede evitar medir en relación con un patrón de desarrollo histórico cuyo modelo es, para él, el europeo occidental. Eso explica por qué, desde Roma, el contacto con los restos de la ciudad lo lleva a meditar sobre las dificultades del reciente proceso de urbanización en Sudamérica:

... la comparación con la obra de los siglos, si en muchísimas cosas certifica la natural inferioridad de nuestra infancia, da su justo valor al esfuerzo que ha permitido levantar del suelo generoso, entre las convulsiones y las fiebres de nuestra formación política, ciudades como Buenos Aires, como Santiago, como Montevideo [... $]^{29}$.

28 José Enrique Rodó, "En Barcelona”, en Obras completas, p. 1191.

29 José Enrique Rodó, "Al concluir el año", en Obras completas, p. 1227. 
Pasajes como este explican por qué, en Rodó, la geografía adquiere un rol alegórico ${ }^{30}$. El viaje a Europa se convierte, así, en un viaje a las raíces histórico-culturales, latinas, de este cronista que proclamaba, en Barcelona, "Civis romanus sum!'31. Desde esa matriz especular, percibe en el conflicto entre Cataluña y la España castellana una similitud con la situación americana y la forzada adecuación de la realidad a la legislación espańola, desde los tiempos de la conquista. El cronista pone en la voz de su interlocutor catalán una explicación de tenor histórico-sociológico acerca de la relación entre ley y tradición en Cataluña, que culmina extrapolándose al contexto americano:

... la legislación de Castilla, adaptada violentamente a nuestro medio [Cataluña]. Propósito tan fuera de lugar como si nosotros hubiéramos querido imponer en Castilla nuestro derecho consuetudinario. Desde entonces la ley y la costumbre marchaban divergentemente en muchos puntos, y esta divergencia no se prolonga sin impotencia de la ley o sin tortura de la realidad. Ejemplo de ello es el permanente desasosiego de vuestras repúblicas americanas, heridas desde la cuna por la escisión de las leyes y los hábitos $[\ldots]^{32}$.

Siempre en esta línea que encuentra en la Europa latina claves de comprensión de las sociedades hispanoamericanas, la multiplicidad de ciudades itálicas con idiosincrasia propia pero que estaban llevando adelante, con éxito, el programa político de la unificación italiana, le sirve para reflexionar sobre las posibilidades futuras de integración latinoamericana, a pesar de las diversidades regionales. O sea que Europa funciona como un observatorio privilegiado para hipotetizar acerca de procesos que bien podrían darse de modo homólogo en la América Latina:

En este maravilloso suelo de Italia, donde los ojos leen cómo la unidad de una tradición y de un espíritu, aunque largos siglos parezcan negarle fuerza ejecutiva, concluye por encarnar en realidad incon-

30 Coincidimos en este punto con Teresa Cirillo Sirri, "Oltre l'isola di Ariel. Rodó in Italia”, Annali. Sezione romanza, XXXIX, 2 (1997), p. 292.

31 José Enrique Rodó, "En Barcelona”, en Obras completas, p. 1193.

32 José Enrique Rodó, "El nacionalismo catalán. Un interesante problema político”, en Obras completas, p. 1197. La bastardilla es nuestra. 
movible, me he dicho infinitas veces que, si aún está para nosotros lejana la hora de una afirmación política de nuestra unidad, nada hay que pueda demostrar mejor el boceto ideal de ese cuadro futuro que la aproximación de las inteligencias y la armonía de las voluntades $[\ldots]^{33}$.

Esta clase de operaciones son posibles porque la latinidad opera para él como una suerte de plataforma que, desde la matriz cultural, permite inferir rasgos de desarrollo social en términos más amplios. Por eso dice, respecto de Nápoles, que "no se descaracteriza. En lo bueno como en lo malo, continúa siendo esencialmente espańola” y llega a afirmar que "participa de Hispanoamérica", gracias a lo cual puede reconocer en la ciudad italiana "cosas que me parecían del terruño, líneas y matices de mi ciudad nativa, en lo que ésta tiene aún de característico, de tradicional, de pintoresco" 34 .

Es evidente, en ejemplos como los que anteceden, cómo la función escrituraria en Rodó excede la dimensión estética, se vincula a su experiencia de hombre público y a la actuación en la gestión política que caracterizó parte de su biografía, para desempeñar el rol más amplio de conductor espiritual o ideólogo, típico de muchos intelectuales en este período ${ }^{35}$. Un rol cuya misión pedagógica se potencia si se atiende a su participación en medios como $C y C$, donde la faceta educativa del intelectual tiene un foro privilegiado. En palabras de Gutiérrez Girardot, "Para Rodó, el arte tiene una alta misión ética [...] que, pese al pathos con que Rodó la formula [en Ariel], tiene que concluir necesariamente en eso que se llama pedagogía, la que fue doble: educación del espíritu y educación continental"36.

Las mismas crónicas ponen en evidencia esta función pedagógica del intelectual en un pasaje que escenifica la condición definitoria del sujeto biográfico Rodó como maestro de la juventud, cuando un grupo de universitarios latinoamericanos que se encontraban en Italia, reconoce en él a una figura magisterial y, en una suerte de evasión temporo-espacial,

33 José Enrique Rodó, "Al concluir el año", en Obras completas, p. 1226.

34 José Enrique Rodó, "Nápoles la española”, en Obras completas, p. 1240.

35 Ángel Rama, "La modernización literaria latinoamericana (1870-1910)", en La crítica de la cultura en América Latina, Caracas, Biblioteca Ayacucho, 1985, p. 91.

36 Rafael Gutiérrez Girardot, Modernismo. Supuestos históricos y culturales, México, FCE, 1988, p. 59. 
instala en una conversación de resonancias arielizantes la visión de una América futura:

... he aquí que, de vuelta a mi alojamiento, me envuelve de improviso una onda fervorosa de juventud, de alegría, de entusiasmo y de patria. Es un grupo de jóvenes venezolanos, que siguen en esta ilustre Universidad sus estudios de medicina y que, conocedores de mi presencia, me forman, para mis restantes horas de Pisa, el más afectuoso y grato acompańamiento que yo hubiera podido imaginar. Arielizamos en sobremesa platónica; recordamos largamente la América lejana y querida, y les oigo, con íntimo deleite, sobre aquel fondo de grandezas muertas, levantar los castillos de las tierras del porvenir ${ }^{37}$.

Pero la visión utópica sobre el futuro de América se contrapone a las imágenes de la guerra absurda que se desarrollaba en Europa y que, en virtud del lugar modélico que ocupaba la producción cultural de este continente para Rodó y la gran mayoría de sus coetáneos latinoamericanos, no podía sino significar una suerte de desencanto civilizatorio. Aun en pasajes que procuran la celebración del modo de vida latino, que el cronista presenta como jovial y optimista a pesar de las dificultades, se deja entrever la situación de inestabilidad y riesgo para el viajero en un mundo que se deshace:

... Mientras el golpe del cañón deshace, palmo a palmo, las fronteras, y los hilos de sangre descienden por las vertientes alpinas, el alma despreocupada y ardiente de la raza sigue entonando, en las ciudades bruñidas de sol, su eterna canción de juventud y de alegría. A no ser por la oscuridad nocturna de las calles, en previsión de los ataques aéreos, y por las relativas incomodidades de la presentación a la Cuestura, para la dichiarazione de soggiorno, nada haría sospechar al viajero que no se vive en tiempo de paz. ¡Cuánta mayor tristeza he visto yo difundirse en la atmósfera de Montevideo, durante nuestras temporadas de guerra civil, que en el ambiente de estas ciudades italianas, hasta cuyas puertas llegan las llamaradas del más atroz encendimiento de guerra que hayan presenciado, ni acaso puedan presenciar, los siglos! ${ }^{13}$

37 José Enrique Rodó, "Recuerdos de Pisa”, en Obras completas, p. 1207.

38 José Enrique Rodó, "Anécdotas de la guerra”, en Obras completas, p. 1220. 
El "atroz encendimiento de guerra" resulta así constatado pero no explicado ni justificado, como en las palabras del oficial que había escrito el diario glosado en "Un documento humano": "No concibo cosa más estúpida que esta guerra de medio mundo contra el otro medio, tanto más cuanto que creo que después de ella las cosas quedarán, poco más o menos, como antes" ${ }^{39}$. Ninguna crónica, quizás, más clara en su alegorización de este desencanto civilizatorio que "Los gatos del foro trajano", comparados con "seres de degeneración y de parodia: degeneración y parodia de la fiera", animales que, adueñados "de aquellos despojos de la grandeza imperial", conducen al cronista a "ver cifrado en este caso un carácter constante de las decadencias", una decadencia que está agazapada en los tiempos modernos: "Somos, para los antiguos, gatos para fieras" 40 . Frente a la decadencia, la irracionalidad y esta suerte de desencanto ante la violencia desatada en el seno de la civilización europea, aparece la posibilidad de que la tradición y la cultura latinas trasladen su eje al continente americano, en un pasaje que, como tantos otros en Rodó, es una alegoría construida a partir de la visión de un objeto de arte, en este caso, la estatua de la loba capitolina:

Esto pensaba al subir las gradas del Capitolio, cuna y altar de la latina estirpe. [...] Y me acerqué a la jaula de la loba que mantiene, allí donde fue la madriguera de Rómulo, el símbolo de la tradición inmensa en tiempo y en gloria; y la vi revolviéndose impaciente entre los hierros que la estrechan. $Y$ me parecía como si, en su presagiosa inquietud, la nodriza de la raza mirase a donde el sol se pone y buscara, de ese lado del mundo, nueva libertad y nuevo espacio ${ }^{41}$.

Sintetizando lo expuesto hasta aquí, es evidente que la escritura cronística de Rodó es otra faceta más de su rol como intelectual al servicio de un proyecto civilizatorio $^{42}$ y que, en ese marco, no hace sino confirmar su

39 José Enrique Rodó, "Un documento humano", en Obras completas, p. 1224.

40 José Enrique Rodó, "Los gatos del foro trajano”, en Obras completas, pp. 1236-1237.

41 José Enrique Rodó, "Al concluir el año", en Obras completas, p. 1227.

42 Sobre el modernismo civilizatorio, afirma Gonzalo Aguilar que se caracteriza por su actitud pedagógica y antiburguesa, su confianza en la palabra y su creencia en el papel privilegiado del intelectual como consejero o denunciante. El rasgo central de esta tendencia es tratar, desde la cultura, de dotar de sentido y rectitud a la razón 
vocación de guiar los derroteros intelectuales, políticos y morales de un público masivo, que veía ampliar simultáneamente su acceso al consumo cultural y al ejercicio de la ciudadanía. Un ejercicio pedagógico necesario si se acepta que la visión de la guerra europea, en sus crónicas de viaje, articula el desencanto ante los aspectos irracionales y decadentes de la modernidad occidental con la promesa de una nueva utopía para la raza latina, esta vez en tierras americanas.

instrumental civilizadora (Gonzalo Aguilar, "Modernismo", en Términos críticos de sociología de la cultura, dir. Carlos Altamirano, Buenos Aires, Paidós, 2008, p. 182). La literatura de viajes del período, del cual la crónica es una forma destacada, se relaciona estrechamente con el proyecto civilizador (Julio Ramos, op. cit., p. 146). 